

Tate, M., Bongiovanni, I., Kowalkiewicz, M. and Townson, P. (2018) Managing the

"Fuzzy front end" of open digital service innovation in the public sector: A

methodology. International Journal of Information Management, 39, pp. 186-198.

There may be differences between this version and the published version. You are advised to consult the publisher's version if you wish to cite from it.

http://eprints.gla.ac.uk/155770/

Deposited on: 9 February 2018

Enlighten - Research publications by members of the University of Glasgow http://eprints.gla.ac.uk 


\title{
Managing the "Fuzzy Front End" of Open Digital Service Innovation in the Public Sector: A Methodology
}

\begin{abstract}
There are many obstacles to effective open innovation in the public sector context, especially at the "fuzzy front end" (FFE), where the need or opportunity is known but serious resources have not yet been committed to possible solutions. In this paper, we report on a theoretically inspired and practically tested methodology for FFE public sector digital innovation. The methodology was purpose-built for the context and has been progressively refined using reflection-on-practice, but broadly consists of a hybrid of private sector open innovation practices, and agile software development processes. We outline the background, context, principles, stages and artefacts. Then we evaluate the method in terms of barriers and opportunities to FFE public sector innovation. We note that establishing the necessary context: a nurturing environment; cross-agency commitments in cash and in kind; and boundary spanning appointments, is as important to success as is the detailed execution of the method.
\end{abstract}

\section{Introduction}

There is worldwide interest in public sector service innovation. This phenomenon is driven by factors that include: a changing population profile with different service needs; an increasing use of digital platforms; a decreasing appetite for large government; and a move towards contestable, community-based, or public-private hybrid models. Public agencies are aiming for a more collaborative and participative relationship with stakeholders (Denhardt \& Denhardt, 2000; Paagman et al., 2015), and hope to harness digital technologies to achieve this (for example, Dunleavy, Margetts, Bastow, \& Tinkler, 2006; OECD, 2016). Both public and private agencies are committing to open innovation processes - meaning that valuable ideas can come from inside or outside the organization (Chesbrough $\&$ Spohrer, 2006) - and may involve working co-operatively with partners in alliances, informal cooperations and joint-ventures (Gassmann \& Enkel, 2004). A major aim of open innovation is to access valuable knowledge from a range of external resources (Esterhuizen, Schutte, \& du Toit, 2012; Lee, Olson, \& Trimi, 2012; Nambisan, 2008). There are important differences between public sector and private sector innovation. Public sector innovation is typically aimed at services rather than products; improved performance and public benefits rather than competitive advantage; and requires more interaction, negotiation and dispute resolution with stakeholders (Cunningham \& Kempling, 2009; Lee et al., 2012). Other issues include: the difficulty of innovating in silos due to the absence of an integrated approach across government, engaging users, forming appropriate partnerships (Bertot, Jaeger, \& McClure, 2008), inflexible cultures, legal requirements, a need for inclusiveness and diversity, and lack of a policy framework (Uppström \& Lönn, 2015). 
In addition to these general issues, many large organizations, both public and private, struggle with what has been described as the "fuzzy front end (FFE)" of innovation (Smith \& Reinertsen, 1992). This is the "fuzzy zone between the time when an opportunity [or need] is known and the time when serious effort is devoted to the development project" (Gassmann \& Enkel, 2004, p. 4). Surfacing good ideas, and deciding which ideas to pursue, remains a challenge for many organizations.

Issues of innovation for citizen-centric government services have recently attracted a great deal of scholarly attention. Recent studies have primarily focused: 1) at a high level, on the logic and governance of citizen-centric public services; 2) at an intermediate level, on innovation life-cycles; 3) at a detailed level, on toolkits and deliverables; or 4) on specific innovation drivers such as big-data. At the high level focus, recent studies have concentrated on (among other things): the logic of public services (for example, Osborne et al., 2012); collaborative innovation at different levels of government (for example, Torfing, 2016); and managing the stakeholders in e-government (Rowley, 2011). At the intermediate level, studies on innovation life-cycles (for example, Gassmann \& Enkel, 2004; Kyffin \& Gardien, 2009), provide a high-level overview of the process and steps involved in carrying out innovation. Toolkits and deliverables for innovation are explored by, for example, Bucolo \& Matthews (2011), as well as in many guidelines and white papers from industry sources ${ }^{1}$. There have also been studies on how to leverage specific innovation drivers such as "big and open linked data" (Janssen et al., 2017).

Our paper uses these studies as a point of departure in three ways. First, we offer an in-depth vertical case study, that shows how high-level principles and governance interact iteratively with the overall innovation life-cycle, the selection and development of specific FFE deliverables, and the integration of FFE deliverables into the later stages of the innovation life-cycle. Second, we examine some of the well-recognized barriers and constraints to effective innovation in government, and identify the opportunities that need to align in order to address these barriers. Third, we show how we draw on insights from existing methodologies to create a purpose-built method. Overall, we provide case-based insights into the effective vertical implementation of open innovation, and show how our approach addresses barriers and leverages opportunities. A general framework for the study is shown in Figure 1.

\footnotetext{
${ }^{1}$ A compilation of white papers is available from http://www.ninesigma.com/open-innovationresources/white-papers-and-reports
} 


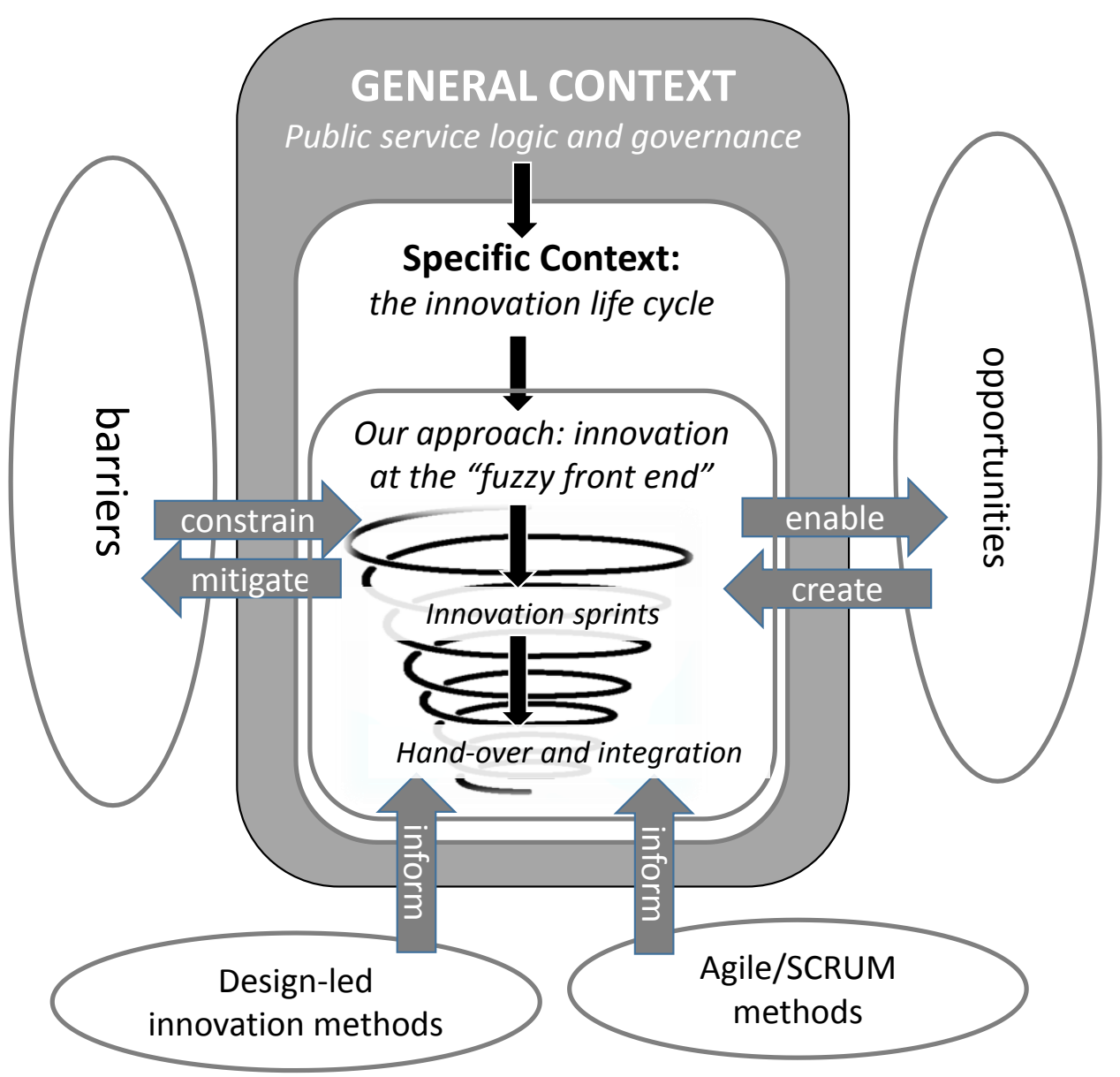

Figure 1: High-level framework for the study

The purpose of this paper is to present a methodology for carrying out open innovation for digital public services, concentrating on the FFE. Following the methodology we briefly describe the theoretical foundations of the method, then illustrate the stages and deliverables. We follow with a discussion and key contributions and a conclusion.

\section{Theoretical background}

\subsection{Innovation Life-Cycles and Types}

Although the actual process followed may be highly iterative, and organizations may enter the process at different stages and back-track to earlier points, engaging in innovation follows a broadly agreed life cycle (Gassmann \& Enkel, 2004; Kyffin \& Gardien, 2009), as depicted in the Figure 2. The life cycle allows ideas to become increasingly concrete and eventually move into testing and market evaluation. As illustrated, the stages up to the development of early models and prototypes are considered by Gassman \& Enkel (2004) to constitute the FFE where our study is concentrated. 


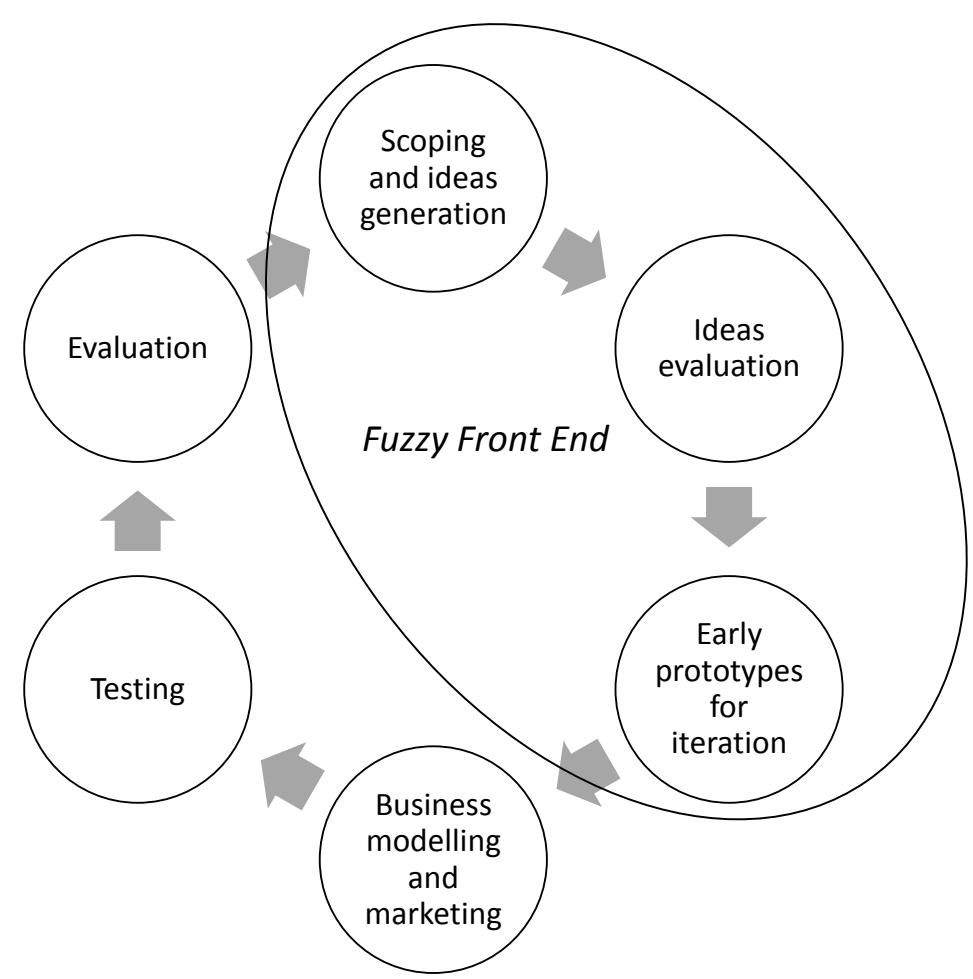

Figure 2: The innovation life-cycle and the FFE

Public sector innovation is a broad concept that can incorporate many types of service innovation: (brand new services or service improvements); service delivery innovation (new ways of delivering existing services); conceptual innovation (new ways of thinking that challenge assumptions underlying services); systematic innovation (new ways of interacting with other organizations or knowledge bases); governance innovation (new ways of engaging citizens and institutions); process innovation (new ways of producing and provisioning services); and communication innovation (new methods of promoting the organization and influencing the behavior of individuals) (De-Vries, Bekkers, \& Tummers, 2016; Windrum, 2008). We aimed to support a range of innovation types in our method.

\subsection{Barriers and Opportunities}

While digital innovation in government is not new, until recently, it faced many challenges. However, a convergence of opportunities arising from the vision and culture of public management, approaches to IT sourcing, and new IT architectures are addressing many of these barriers. A summary of the interrelated barriers and opportunities is shown in Figure 3. 


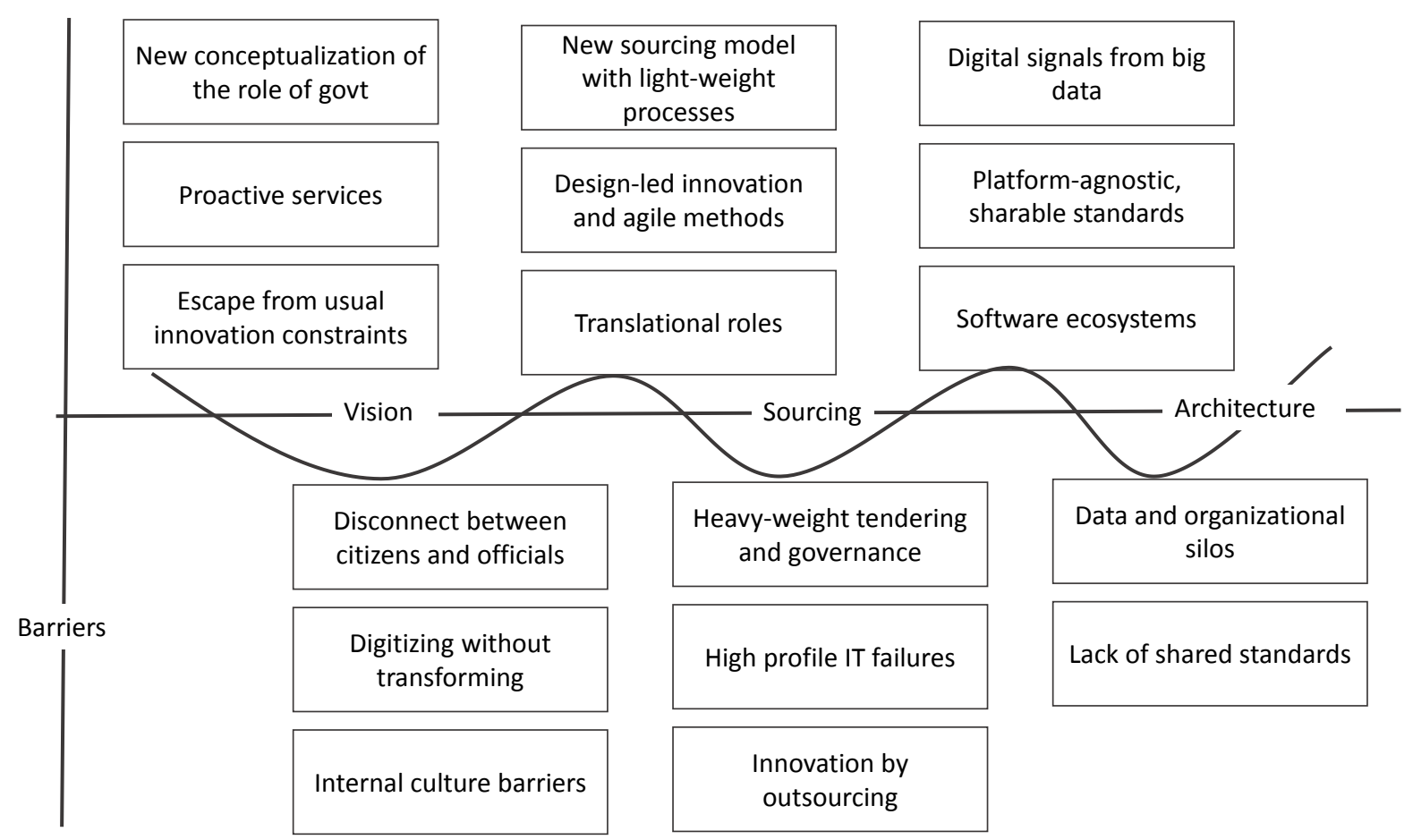

Figure 3: Interconnected barriers and opportunities

\subsubsection{Barriers and opportunities in the vision and culture of public service delivery}

A noticeable deepening disconnect between citizens and government in many parts of the world has been recognized as a global challenge: "there is a fundamental disconnect between citizens around the world and the elected officials that supposedly represent them" (World Economic Forum, 2015, p. 20), and this disconnect has been a barrier to discourse about public services. However, this has also created opportunities for new conceptualizations of the role of government, and a view that democracy needs to modernise itself and actively involve citizens in decision-making processes: "governments should position themselves as the bodies that articulate the issues faced by society, and then strive to create the right environment...to find the solutions" (World Economic Forum, 2015, p. 21). In the academic community, the so-called "New Public Service" vision advocates (among other things) that public agencies should engage in processes of collaboration and shared leadership with stakeholders (Denhardt $\&$ Denhardt, 2000). Technology has been seen as a major enabler of this change.

Although e-government initiatives have been pursued since the 1990s, many early initiatives were not successful in removing barriers to effective citizen engagement. Many early e-government initiatives were simply digitizing government without transforming the design and delivery of information and services, so that citizens were still left with the burden of navigating multiple government agencies to achieve their goals (Gottschalk, 2009). More recently, a vision has emerged of public services that are not only "joined-up" and "customer-centric" but proactive. This means not only responding to, but where appropriate anticipating, the needs of citizens Kowalkiewicz, Rosemann, Reeve, Townson \& 
Briggs., (2016). For example, knowing someone has reached school age, or retirement age can automatically trigger changes in their status, needs, and the kinds of services provided by government agencies.

A further barrier has been the internal culture and processes of government agencies. These have included short term budgetary, planning and political cycles; risk aversion; lack of incentive to change; and unresponsive organizational cultures (see, inter alia, Albury, 2005; Bason, 2010; Bekkers, Tummers, \& Voorberg, 2013). To the extent that digital innovation has occurred, it has typically been an incremental process, and a transformative one (Norris \& Reddick, 2012). Creating the opportunity for public change agents to escape the constraints typical of the public sphere was a major goal of the project reported in this study.

\subsubsection{Barriers and opportunities in public sector sourcing}

Compounding problems arising from the wider environment, barriers to digital innovation in public services also arose from the public sector approach to sourcing IT. In the 1990s there was a belief that the public sector could best access innovation by outsourcing (Moon, Swar, Choe, Chung, \& Jung, 2010). This contributed to a "hollowing out" of public sector IT skills (Tate, Johnstone, Toland, \& Hynson, 2007). However, outsourcing was not a "silver bullet", and governments experienced a succession of high profile public IT failures (see for example Charette, 2005). This resulted in an emphasis on clear requirement specifications and rigorous and heavy-weight tendering and governance processes (Carter-Steel, Tan, \& Toleman, 2009), where contestable competitive tenders and lowest cost suppliers were the preferred means of sourcing IT (Hancox \& Hackney, 1999). These prescriptive processes proved problematic for sourcing innovative collaborative technology solutions to "fuzzy" requirements based around societal problems and needs, rather than specific and wellarticulated sets of requirements (Hommen \& Rolfstam, 2009) (Martin \& Webb, 2009, p. 129). It has also been suggested that innovation involving a wide range of stakeholders is challenging because it is resource-intensive and costly (Bertot et al., 2008).

Providing an opportunity for effective sourcing of FFE innovation was a major goal of the project we report on. We aimed to develop an approach that would provide a new sourcing model to fulfil the desire for a more proactive and collaborative approach to digital public services; the desire to escape the constraints of innovating in the public sphere; and the need for developing a light-weight process aimed at the FFE. While the exact configuration is unique, we drew on a number of sources to inform its development. Primary among these were initiatives led by the private sector in design-led innovation and agile software development methods, which are described in more detail below. Another important opportunity was the recognition of the need for "translational" roles (Norman, 2010); key people who have credibility in both academic and practitioner environments and can bridge the boundaries between them. 


\subsubsection{Barriers and opportunities in IT Architecture}

Even assuming that public agencies shared a clear vision of less siloed government, genuine "citizen centric" digital government services have proved difficult to deliver. Barriers included the difficulty of re-engineering back-end processes and spanning data and organizational silos (Bekkers, 2009). There has also been a tendency to use closed, proprietary technical solutions, so that even when there is a willingness to carry out more collaboration between agencies, there has been a lack of shared technical standards and data definition standards (Janssen, Charalabidis \& Zuiderwijk, 2012).

Many of these barriers are mitigated by the opportunities arising from new generations of IT architecture. Big data analytics allows individual data-points to be considered collectively and in comparison to data of those similar to us either geographically, demographically or behaviorally. This can provide insight into the events, life experiences, and patterns and trends in society. Kowalkiewicz et al., (2016) coined the term "digital signal" for a convergence of individual pieces of digital data that indicate an event, trend, or preference of an individual, business or an object, in a particular context.

The maturity of platform-agnostic, sharable standards, notations and architectures represents another opportunity. For example, this project used JSON (JavaScript Object Notation) in its technical prototypes. JSON is a lightweight data interchange format, which is relatively easy for humans to read and write, and possible for machines to parse and generate ${ }^{2}$. It is language independent, but uses conventions similar to popular programming languages. ${ }^{3}$

Open standards allow the development of digital services and service systems that cross organizational boundaries and span multiple organizations, referred to as software ecosystems. Software ecosystems have been defined as a "set of businesses functioning as a unit and interacting with a shared market for software and services, together with the relationships among them" (Jansen, Finklestein \& Brinkkemper, 2009, pp187-188). These relationships are "frequently underpinned by a common technological platform or market and operate through the exchange of information, resources and artefacts" (Jansen et al., 2009, p 188). Software ecosystems can span siloed public agencies, or link public, private, and community groups and depend on open standards. At a technical level, open standards and ecosystem approaches are necessary to support and enable the vision of the "new public service" that collaboratively negotiates and brokers solutions to social problems with various stakeholders (Lee, Baek, \& Jahng, 2017).

\subsection{Methodologies}

Our approach drew extensively on two specific design and development methodologies.

\subsubsection{Design-led innovation}

\footnotetext{
${ }^{2}$ www.json.org

${ }^{3}$ Ibidem.
} 
Design-led innovation is a problem or opportunity-based approach to innovation where early versions of new design artefacts, and the associated business vision and business models co-evolve. Techniques and practices are becoming mainstream, drawing on a wide range of disciplines, including business, ethnography, design, and cognitive science (Ogilvie \& Liedtka, 2011). Design-led innovation focuses on customer empathy, ideation, experimentation, constant evaluation, and prototyping (Hildenbrand \& Meyer, 2012). Designer teams, business managers, academics and subject matter specialists work rapidly, collaboratively and iteratively with customers (Bucolo \& C, 2013). A key aspect of design-led innovation is deep customer engagement. Design artefacts such as customer journey maps, that communicate 'a day in the life' narratives of users of the proposed service innovation, form the basis of future solutions and a set of criteria that proposed solutions can be evaluated against. Then these understandings are translated into prototypes and early models of solutions. The organization is challenged to constantly ask why the problem occurred, rather than (initially) how can it be solved. (Bucolo \& Matthews, 2011). Design-led innovation produces a range of artefacts that enable FFE design concepts to be communicated, socialized and iterated rapidly without a large investment.

\subsubsection{Agile Digital Artefacts Development and Scrum Methodology}

The scrum methodology served as a technique to develop agile digital artefacts. Disaffection with monolithic software projects motivated the agile software movement, which focusses on producing working software, rather than producing documentation, and welcomes, rather than resists, changing requirements. Agile development is iterative, evolutionary, and is conducted in short cycles (Highsmith $\&$ Cockburn, 2001). One frequently used methodology for agile development is "scrum" (Schwaber, 2004). Development time is divided into short work cadences, known as sprints, typically one week or two weeks long (Schwaber, 2004). Sprints are intense periods of concurrent conceptualization and development. Each sprint has its own set of requirements selected from the "backlog" of overall requirements. The sprint is then planned, and its specific requirements are similarly triaged and prioritized. Daily scrum meetings of team members maintain focus, as do regular inspections and reviews of the software that has been developed. At the end of every sprint, a sprint retrospective is held to look for ways to improve the next sprint.

\section{The context of the study}

The context of the study was a partnership between local and national government agencies, academia, and the private sector, intended to promote digital innovation in the state of Queensland, Australia. This was exemplified in the creation of a multi-agency "one-stop shop" umbrella for integrated digital service delivery ${ }^{4}$. An early decision was made to establish a senior position to act as

\footnotetext{
${ }^{4}$ https://www.qld.gov.au/dsiti/digital/one-stop-shop
} 
a focal point for digital innovation. The vision was to create a safe, neutral, collaborative space, unconstrained by organizational politics and normal tendering and sourcing cycles, where creative ideation and open innovation could be carried out. A new Chair in Digital Economy ${ }^{5}$ was established as a jointly funded venture between QUT, PricewaterhouseCoopers $(\mathrm{PwC})$, Brisbane Marketing (Brisbane's economic development board, a wholly-owned subsidiary of the Brisbane City Council), and the Queensland Government. The Chair was to champion collaborative engagement models and generate innovative digital solutions for complex social problems such as youth homelessness, reducing bureaucracy for small business start-ups, increasing citizen engagement with policy-making, and measuring and improving quality of life for citizens. The projects would have a digital focus (although did not necessarily need to produce a digital artefact), and would be forward-looking, but feasible.

A major vehicle to achieve this was the development of an open innovation methodology purposebuilt for complex social problems. The methodology was developed, practised and refined within a reflective practice paradigm over a two year period (Schon, 1983). The authors were embedded in a team with a flexible and changing membership (depending on the stage and nature of the problem being addressed) which included consultants, IT companies, academics, community groups and public servants.

\section{Overview of the Method}

\subsection{Articulating the guiding vision and governance}

The partnership was guided by a new digital public service vision to: maintain the role of public agencies as trusted service providers; move from a reactive to a proactive model of service provisioning; and harness the capabilities of new technology. By customer-centered it was understood that customers' circumstances, needs, life events and "journeys", being understood, expressed and shared as design artefacts, would drive the development of potential solutions, rather than meeting the technical or organizational needs of participating agencies.

By proactive service provisioning based on new technology, it was understood that it is increasingly possible to foresee many of the customers' future needs, rather than waiting for them to request a service. Delivering proactive services requires, firstly, prediction based on data analytics (Davenport, 2013), then modelling of optimal behaviors which may be potentially performed automatically (proactively) for the customers. The idea of a proactive organization (Kowalkiewicz, et al., 2016) is one that uses digital information and analytics to actively offer services for needs that customers have not yet recognized themselves.

The establishment of the Chair in Digital Economy could be considered a first, essential step in the methodology as it provided a focal point for management and governance of the innovation process,

\footnotetext{
${ }^{5}$ www.chairdigitaleconomy.com.au
} 
including the ability to command resources, facilitate resolution of conflicts between stakeholders, set policy, and act as a "translational" role at a senior level (Norman, 2010).

\subsection{Iteratively evolving policy, architecture and design principles}

Unlike the private sector, many public service innovations cannot occur in isolation, as a policy framework and an integrated approach across government is required (Uppström \& Lönn, 2015). Multiple inhibitors may exist, including lack of integration, legacy system platforms, lack of effective management of cross-agency processes and business rules (Uppström \& Lönn, 2015). Customercentered government services frequently require key infrastructure services like digital identity and data sharing, many of which did not exist in Queensland at this stage. These issues were addressed in a novel way. Aiming to solve all integration issues up-front could be extremely costly and timeconsuming, with no guarantee that the policy and infrastructure solutions developed would meet the eventual requirements of the new wave of digital services. Instead, the method surfaces and articulates key policy and architecture assumptions and requirements iteratively as they are needed, and proceeds as if they already existed. Architecture, policy and design principles are recognized as intertwined and also as being, to varying degrees, emergent from the innovation process. Rather than trying to "solve" whole-of government policy and IT architecture and design issues up-front before any innovation was carried out, these issues were allowed to co-evolve. In some cases, partial or temporary solutions to infrastructure requirements were developed, using open architectures and standards that would enable later scaling to an integrated solution. For example, some new welfare services required a single point of authentication and the ability to carry out data sharing between welfare agencies and the tax office. Services like identity management were developed iteratively and on a problem-based basis, rather than as a "big bang". They emerged incrementally, constantly, and in a problem-driven manner. As part of each innovation cycle, supporting policies, architectural and design principles and infrastructure were developed minimally to support the immediate requirement and contribute to the growing body of knowledge and the set of design artefacts for an integrated solution for authentication and data sharing. We show the co-evolution of the vision, architecture and design principles in Table 1.

Table 1. Co-evolution of vision, architecture and design principles

Co-evolution of cross-agency customer-centered policy, architecture and design principles 
Customer consent to data sharing, with clearly articulated data sharing policies and practices

Customer authentication and access to services

Triggers for events
Policy: For each new service innovation, all agencies involved, and the customer, will develop a consistent understanding of customer consent for data sharing. This clarifies dependent and independent consent, and situations when customers can and should have control over their personal data. These understandings build towards a data sharing framework.

This is essential to the evolving vision of the role of public agencies as trusted partners. It guards against intrusiveness and surveillance, and also supports compliance with key social contracts between citizens and government agencies.

Architecture and design: The capacity for agencies to ethically share personal data will exist. A customer can nominate what information is shared between various agencies and then agencies can appropriately lookup, share, and validate records. However, restrictions on data sharing consent may restrict the ability of public agencies to offer services. These restrictions need to be fully transparent.

Example: For example, child immunization records are private (in general) but in the event that a citizen requests financial support for their child to attend a child care center (independent consent), the immunization status of their child may be checked (dependent consent). Refusal to consent to checking immunization status may result in an inability to access financial support services for child care.

Policy: As far as possible, users will be able to access government services without authentication.

Architecture and design principle: Non-authenticated users will still access services, but personalization will be limited to information available and shared by the user (e.g. geographic location).

Example: A homeless person should be able to investigate possible assistance options without disclosing their identity. The options could be tailored based on the location of the enquiry. However, they will not be able to seek financial assistance without authenticating.

Policy: For a consistent experience across agencies, all services need to be understood to be associated with one or many different customer triggers.

Architecture and design principle: The development of new services will contribute to building a common and consistent vocabulary of life event and outcome-based triggers across government, and additional services will be matched to this vocabulary.

Example: Changes in circumstances such as "retirement", "unemployment" or "homelessness" need a consistent, agreed and nuanced vocabulary. A person may have reached the age when they are eligible for retirement benefits, but may be working full or part time. A "homeless" person may have insecure and temporary accommodation but without seeking assistance in homeless shelters or sleeping rough. These terms need to be consistently understood and defined across agencies, and associated with appropriate services. 
Shared platforms and integrated federal, state and local government service delivery
Policy: Platforms and standards for cross-agency data sharing will exist.

Architecture and design principle: A shared digital platform will allow agencies to publish their content into a common area, which is then married against customer data (according to data-sharing consents and requirements). This is supported by open standards and data-as-a-service, and can be developed iteratively monolithic up-front infrastructure solutions are not required.

Example: Agencies will be able to request information required for service delivery on request and in accordance with customer consents.

\subsection{Understanding and triaging requirements}

There is a universe of potential requirements for new or improved public services. A systematic process was undertaken to shortlist government services from over 2000 services offered by 20 agencies based on their potential to be redesigned as innovative and proactive services. Services that were primarily informational were removed; followed by simple transactions (for example, booking and paying for a camping spot); followed by complex specialized services with a small number of customers (for example, processing disability permit applications); followed by specialist, ad-hoc, one-to-one services (for example, providing feedback on a large property development application). The overall number of customer transactions accessing the service and the potential social and business impacts of transforming the service were also considered. Finally, twenty-one service challenges were shortlisted, consisting of a total of 96 individual service interactions, to form the initial project scope. From these, an initial three were selected for innovation cycles. This number was later extended to ten, and the project is ongoing at the time of writing.

\subsection{Digital service innovation sprints}

A purpose-built digital innovation sprint methodology was adopted for the FFE of the selected service innovation challenges. Inspirationally, the innovation sprint method was a hybrid of design-led innovation and scrum software development methods, customized to the public sector context and refined through reflection-on-practice (Schon, 1983).

The sprint approach was aimed at managing cost and risk, and maintaining a focus on producing tangible results. The sprints were design-driven, taking a customer-centered approach to rapid innovation, delivering proof-of-concept (POC), digital artefacts, and qualitative academic reports. However, we cannot emphasize enough that the methodology is wider than the sprints. The sprints could not have occurred in isolation. Having the establishment of the Chair in Digital Economy as a champion and boundary-spanner; agreement on the guiding vision, principles and governance; and an open approach to co-evolving policy, architecture and design principles (so the sprints would not get bogged down in these issues); were critical antecedents. 
The proactive services were to be designed to prototype or proof-of-concept stage - the FFE of the innovation cycle. Sprints were held in a dedicated team space at the Queensland University of Technology. Each sprint was limited to 10 working days, with a focus on achieving tangible outcomes. A list of six completed sprint topics is included as Appendix A. The sprint teams were flexible, multidisciplinary, and "translational" (Norman, 2010), and varied depending on the nature of the problem. Broadly, all teams included: a sprint leader, senior officials from departments involved with the problem under investigation, a representative of the Queensland Government's digital strategy team, academic researchers with specialized knowledge in the area, representatives from the Queensland Government's design agency, and technical specialists as required.

The sprints aimed to identify and define highly complex, entrenched and wicked problems. These were organizational or strategic challenges, where there were multiple, interacting issues that had evaded solutions in the past. Examples included: "how do we attract digital businesses and capital to Queensland?", and "how do we engage citizens more effectively in health and well-being initiatives?". The sprints focused on gaining deep insight; finding new perspectives; and proposing new solutions that had not been considered before. Some had a strategic focus, others had a more technical focus. The method is applicable to innovation for many different service types, and to both strategic and technical challenges.

\subsection{Sprint stages and artefacts}

The sprints follow a broadly linear process, from problem definition and articulation through to the production of artefacts, although continual iteration and refinement occurs. An overview of the sprints and the activities carried out at each point, is shown in Figure 4. The process moves from deep understanding of the problem and customer empathy (why this is a problem) through generating ideas as to how the problem might be addressed, to early prototyping and evaluation (what will be delivered).

Before the intensive 10-day sprint period, the problem is incubated and scoped. Stakeholders are identified and the detailed sprint workshop process is designed. The first phase of the sprint concentrates on a customer need or problem, and the opportunity to develop a proactive solution. The research phase includes seeking detailed information about the customer segments involved; why the problem identified is a problem for them; what their needs are; what is already known about the problem; and existing strategies to address it. Understanding the customer is supported by several research strategies. Interviews with stakeholder groups increase the empathy of the sprint participants with the customer need being addressed and deepens their commitment to achieving a solution. Desktop research involves searching and synthesizing academic literature to clarify aspects of the problem, and identify any existing initiatives and best practice world-wide. Data gathering includes analysis of non-academic sources.

The design stage departs from traditional scrum sprints, as it involves service design, not technical system design (although technical artefacts may be involved). The broad format of scrum sprints is 
followed, but many of the techniques used were customized from design-led innovation. Design of public services requires recognition that most social service requirements are temporary states that people move into and out of. For example, a person may move from being employed to being retired, a child may move from being enrolled at day care to being enrolled at school, and a person may move from being homeless to being in temporary accommodation, to being in permanent accommodation. Detailed workshops with a range of stakeholders contribute to understanding of the customer journey and refinement of the understanding of the problem.

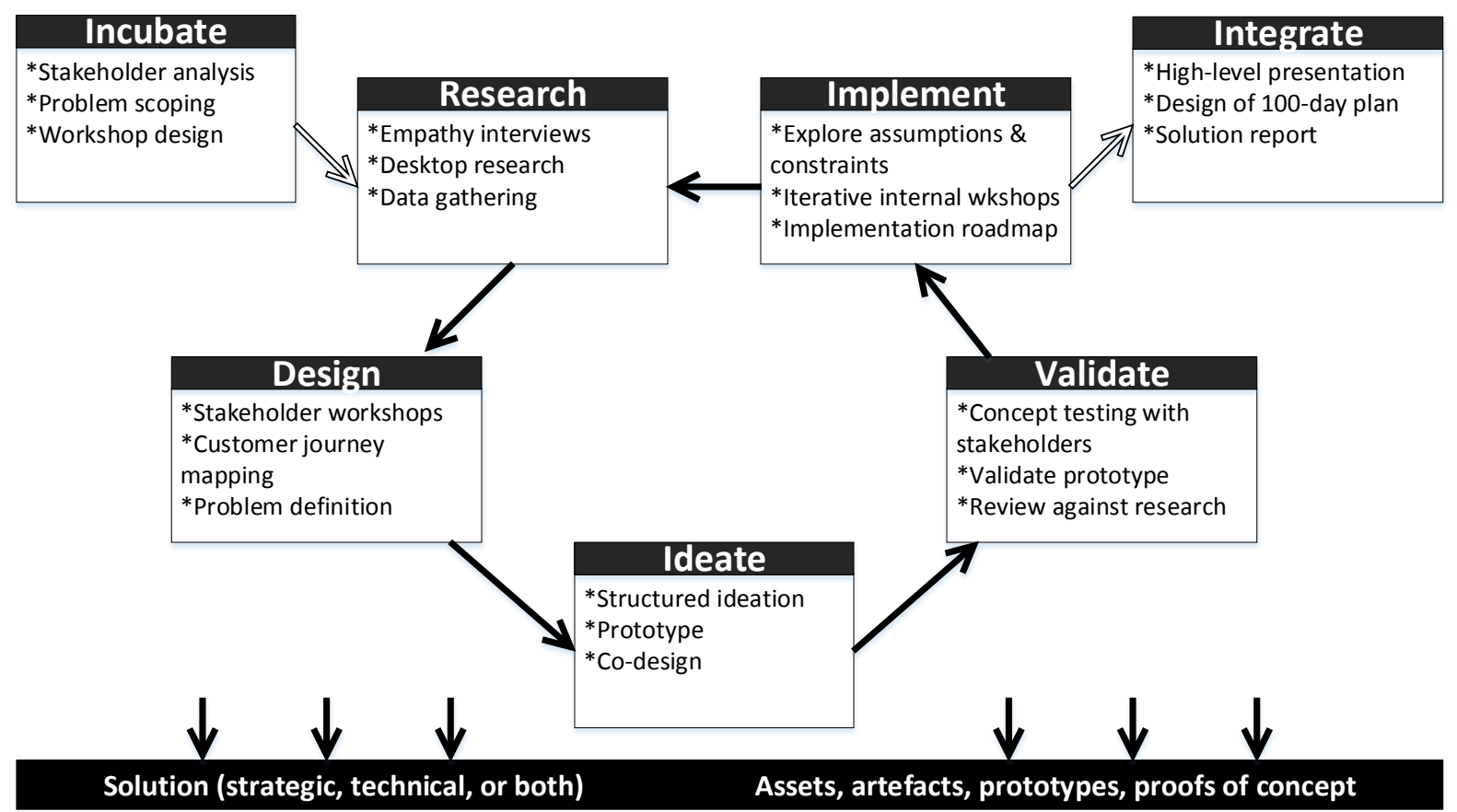

Figure 4: High level overview of the Digital Innovation Sprint Cycle

Ideation begins to move the sprint towards the development of artefacts and draws extensively on design-led innovation approaches. The participants work in small groups, brainstorming about what a solution might look like, and what components it should contain. The aim is to generate the maximum number of ideas. These can then be prototyped rapidly, and validated with stakeholders and against academic research, customer-centric design artefacts and best-practice. Finally, a finished set of artefacts and assets is completed, including understanding of the assumptions and constraints (these may in some cases result in further refinement of the governing principles), and a roadmap for how the prototype or POC should be moved into implementation.

For the solutions that are intended to proceed into implementation, a post-sprint activity is carried out to integrate the sprint deliverables into the wider organizational context. This includes presentations to senior decision-makers and stakeholders, a "100-day plan" for the next steps of implementation, and a detailed report on the characteristics and requirements of the solution. 
A set of example artefacts from the sprints are provided in a table in Appendix B. The table describes the artefact, its purpose, and provides a link to the research literature that informed the design of the artefact. In particular, we draw on design-led innovation approaches, tools, and techniques (Kyffin \& Gardien, 2009; Norman, 2010; Ogilvie \& Liedtka, 2011), while also drawing heavily on the scrum "sprint" approach and (in some cases) developing more traditional software and service specification and development deliverables like wireframes and JSON specifications. The sprint stages and artefacts were also progressively refined as part of regular "reflection-on-practice" as the sprint cycles continued. The intention of this paper is not to introduce each sprint deliverable in detail, as they all have a detailed provenance in other methodological literature (examples are cited in the table in Appendix B).

Many of the sprint activities involve getting to know the customer deeply; understanding the characteristics of a customer-centric service, and understanding their needs at each stage as they move through the process of solving the problem. For example, a customer persona is developed, and a detailed "journey map" that describes a typical path through the problem space. Only then can candidate solutions begin to be developed. The "design" stage involves service design, not system design. The ideate stage draws on "fail-fast" design-led innovation thinking, and aims to generate alternative solutions. These can draw on a range of existing software components and systems (for example, mobile platforms, social media applications or Google maps location-based information), new software components, interaction, and user experience prototypes, and new or changed organizational processes. A range of participants with skillsets, including service delivery managers from public sector agencies, interaction designers, researchers, and software engineers, all contribute and co-design.

The ideas are regularly tested against the personas and journey maps and other detailed understandings of the service requirements, and simultaneously evaluated for technical feasibility. Immediate feedback from a range of subject matter experts can be obtained as required. Proposed solutions are evaluated to determine to what extent they create value for stakeholders. This does not necessarily mean financial value. Value can be derived from timesaving, convenience, accessibility, and other sources. This process surfaces and rejects a large number of ideas. From the ideation stage, some strong and valuable conceptual service designs emerge. These are then prototyped. Prototypes are tested with customers and stakeholders. Once again, a co-design environment allows rapid iteration and "fast failure". By evaluating solutions that are not complete, unpromising directions may be discarded and promising solutions refined. This is also a very important opportunity to obtain buy-in and ownership from stakeholder groups. Finally, the proposed solution is workshopped with a view to moving into "late innovation", and a roadmap is then developed.

\section{Evaluation and discussion}

The value has been reflected in the ongoing commitment of financial and "in kind" resources by the partners, the continuation of the program, and the migration of approximately a third of the prototypes into the later stages of innovation. The partners have continued to invest in the sprint process, which 
has proved cost-effective, with direct funding, plus thousands of hours of time "in kind", including the involvement of senior civil servants. The method is demonstrably effective in addressing recognized barriers to the FFE of public-service innovation. We summarize this in Table 2. At the time of writing, four sprints have been taken forward and referred to an implementation team to move into late stage innovation.

Table 2: The effectiveness of the method in addressing barriers to FFE digital innovation

\begin{tabular}{|c|c|c|c|c|}
\hline $\begin{array}{l}\text { Management } \\
\text { Level(s) }\end{array}$ & 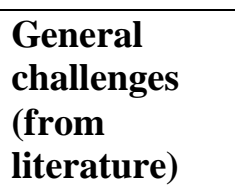 & $\begin{array}{l}\text { Specific challenge } \\
\text { identified in this } \\
\text { case }\end{array}$ & $\begin{array}{l}\text { General } \\
\text { opportunity } \\
\text { (from literature) }\end{array}$ & $\begin{array}{l}\text { Specific Solution } \\
\text { applied in this case }\end{array}$ \\
\hline \multirow[t]{3}{*}{$\begin{array}{l}\text { Logic and } \\
\text { governance } \rightarrow \\
\text { innovation life } \\
\text { cycle }\end{array}$} & $\begin{array}{l}\text { Disconnect } \\
\text { between } \\
\text { citizens and } \\
\text { government }\end{array}$ & $\begin{array}{l}\text { Lack of vision } \\
\text { between multiple } \\
\text { state, federal and city } \\
\text { agencies involved in } \\
\text { service delivery. }\end{array}$ & $\begin{array}{l}\text { New } \\
\text { conceptualization of } \\
\text { role of government }\end{array}$ & $\begin{array}{l}\text { Cross-agency vision of } \\
\text { the "one-stop shop" }\end{array}$ \\
\hline & & & Translational roles & $\begin{array}{l}\text { Creation of the Chair } \\
\text { in Digital Economy as } \\
\text { a "translational" role }\end{array}$ \\
\hline & $\begin{array}{l}\text { Digitizing } \\
\text { without } \\
\text { transforming }\end{array}$ & $\begin{array}{l}\text { Lack of integration } \\
\text { in e-government } \\
\text { initiatives so citizens } \\
\text { needed to traverse } \\
\text { multiple } \\
\text { agencies/websites }\end{array}$ & $\begin{array}{l}\text { Pro-active services } \\
\text { Informed by big } \\
\text { data and digital } \\
\text { signals }\end{array}$ & $\begin{array}{l}\text { Understanding and } \\
\text { triaging service } \\
\text { requirements to } \\
\text { evaluate for and } \\
\text { suitability for "one- } \\
\text { stop shop" and pro- } \\
\text { active service delivery }\end{array}$ \\
\hline \multirow[t]{2}{*}{$\begin{array}{l}\text { Innovation life- } \\
\text { cycle } \rightarrow \text { FFE }\end{array}$} & $\begin{array}{l}\text { Innovation by } \\
\text { outsourcing } \\
\text { and internal } \\
\text { culture } \\
\text { barriers }\end{array}$ & $\begin{array}{l}\text { Challenges are } \\
\text { sourcing open FFE } \\
\text { innovation using } \\
\text { existing tendering } \\
\text { processes, cultural } \\
\text { including issues }\end{array}$ & $\begin{array}{l}\text { New sourcing } \\
\text { model supported by } \\
\text { translational roles, } \\
\text { and escape from } \\
\text { usual constraints }\end{array}$ & $\begin{array}{l}\text { Development of } \\
\text { innovation sprint } \\
\text { approach. } \\
\text { A flexible and neutral } \\
\text { space for collaboration } \\
\text { between public agency } \\
\text { staff, academics, and } \\
\text { consulting companies. }\end{array}$ \\
\hline & $\begin{array}{l}\text { Heavy-weight } \\
\text { tendering and } \\
\text { governance } \\
\text { processes, } \\
\text { and } \\
\text { High profile } \\
\text { IT failures }\end{array}$ & $\begin{array}{l}\text { Challenges in } \\
\text { supporting FFE } \\
\text { especially for } \\
\text { multiple types of } \\
\text { public-sector } \\
\text { innovation and } \\
\text { stakeholders }\end{array}$ & $\begin{array}{l}\text { Light weight } \\
\text { process }\end{array}$ & $\begin{array}{l}\text { Use of the10-day } \\
\text { sprint cycle approach } \\
\text { manages cost and risk } \\
\text { Short-term, highly } \\
\text { focused sprint cycles } \\
\text { Customer-centered } \\
\text { approach supports } \\
\text { many types of } \\
\text { innovation. Examples } \\
\text { are shown in } \\
\text { Appendix B. }\end{array}$ \\
\hline
\end{tabular}




\begin{tabular}{|c|c|c|c|c|}
\hline \multirow[t]{2}{*}{$\mathrm{FFE} \rightarrow$ sprints } & \multirow[t]{2}{*}{$\begin{array}{l}\text { Innovation by } \\
\text { outsourcing }\end{array}$} & $\begin{array}{l}\text { Difficulty in public } \\
\text { sector sourcing of } \\
\text { open FFE } \\
\text { innovation, and } \\
\text { difficulty in working } \\
\text { with multiple } \\
\text { stakeholders }\end{array}$ & $\begin{array}{l}\text { Design-led } \\
\text { innovation and } \\
\text { Agile software } \\
\text { development } \\
\text { methods }\end{array}$ & $\begin{array}{l}\text { Design-led innovation } \\
\text { and Scrum techniques } \\
\text { were hybridized and } \\
\text { adapted for the public } \\
\text { service context. } \\
\text { Flexible team } \\
\text { membership and } \\
\text { format. } \\
\text { A neutral space. } \\
\text { A flexible, open and } \\
\text { multi-disciplinary } \\
\text { "opt-in" team culture }\end{array}$ \\
\hline & & $\begin{array}{l}\text { Difficulty in moving } \\
\text { problems through the } \\
\text { FFE to developing } \\
\text { tangible and } \\
\text { innovative outcomes } \\
\text { that can be integrated } \\
\text { with the wider } \\
\text { technical and } \\
\text { organizational } \\
\text { environment rapidly } \\
\text { and cost-effectively. }\end{array}$ & $\begin{array}{l}\text { Maturity of } \\
\text { platform agnostic } \\
\text { standards, and } \\
\text { software } \\
\text { ecosystems }\end{array}$ & $\begin{array}{l}\text { Each sprint produces } \\
\text { an inventory of new } \\
\text { tangible design } \\
\text { 'assets" which may } \\
\text { include customer } \\
\text { journey maps, } \\
\text { schemas, models, } \\
\text { web-design wire- } \\
\text { frames, prototypes, } \\
\text { processes, principles. }\end{array}$ \\
\hline \multirow[t]{4}{*}{$\begin{array}{l}\text { Sprints } \rightarrow \\
\text { hand-over and } \\
\text { integration }\end{array}$} & \multirow[t]{4}{*}{$\begin{array}{l}\text { Data and } \\
\text { organizational } \\
\text { silos and lack } \\
\text { of shared } \\
\text { standards }\end{array}$} & $\begin{array}{l}\text { Working in the } \\
\text { absence of a } \\
\text { complete } \\
\text { infrastructure }\end{array}$ & $\begin{array}{l}\text { Open standards and } \\
\text { software } \\
\text { ecosystems }\end{array}$ & $\begin{array}{l}\text { Iterative co-evolution } \\
\text { of infrastructure } \\
\text { principles, } \\
\text { architectures and } \\
\text { design components }\end{array}$ \\
\hline & & $\begin{array}{l}\text { Requirement for up- } \\
\text { front negotiation } \\
\text { between agencies } \\
\text { over infrastructure } \\
\text { and standards }\end{array}$ & & $\begin{array}{l}\text { Open standards } \\
\text { support iterative and } \\
\text { scalable infrastructure } \\
\text { development. }\end{array}$ \\
\hline & & & & $\begin{array}{l}\text { The ability to } \\
\text { iteratively abstract } \\
\text { general architectural } \\
\text { principles from } \\
\text { specific innovation } \\
\text { sprints ensures } \\
\text { ongoing alignment } \\
\text { with the emerging } \\
\text { service vision. }\end{array}$ \\
\hline & & $\begin{array}{l}\text { Integrating sprint } \\
\text { artefacts into later } \\
\text { stages of the } \\
\text { innovation life cycle }\end{array}$ & & $\begin{array}{l}\text { The post-sprint } \\
\text { activities, "100-day } \\
\text { plan" for next steps } \\
\text { support the transition } \\
\text { from FFE to late stage } \\
\text { innovation. }\end{array}$ \\
\hline
\end{tabular}




\section{Conclusion}

To our knowledge, this is the first paper grounded extensively in theory and practice, to present a detailed methodology for carrying out the FFE of digital public service innovation. Furthermore, the method has been refined through repeated versions of "reflection-on-practice", and has been proven to be effective. We show how it harnesses current opportunities and mitigates frequent barriers. To do this, we synthesize knowledge from public policy, IT architecture and design, and open innovation sourcing. We emphasize that carrying out effective FFE innovation for digital public services requires an awareness of this interconnectedness and an approach which allows them to co-evolve.

We bridge the gap between an appetite "in principle" for more collaborative and democratic forms of government, supported by digital services, and the challenges of achieving this in practice. A major insight from our study is that this kind of innovation cannot occur in isolated silos and cannot be accomplished by innovation teams or incubators that are too junior, or separated from the wider organization. They require a nurturing environment, commitment and sponsorship at a high level. To be effective, the innovation process must include people with the appropriate authority to carry the innovations forward, so matching the scope and context of the innovations with the team composition is important. We urge attention to senior, boundary-spanning appointments, clear guiding principles, and careful triaging of opportunities as well as engagement with software ecosystems, design-led innovation, and agile software development principles. The public sector and its stakeholder communities need to harness the opportunities the "digital revolution" offers. We commend our method to those seeking to do this more effectively.

\section{Funding}

This research has been supported by the Australian Research Council [grant number DE160100548]; the Queensland Government, in particular, the Department of Science, Information Technology and Innovation

\section{References}

Albury, D. (2005). Fostering Innovation in Public Services. Public Money \& Management, 25(1), 5156.

Ashurst, C., Freer, A., Ekdahl, J., \& Gibbons, C. (2012). Exploring IT-enabled innovation: A new paradigm? International Journal of Information Management, 32(4), 326-336.

Bason, C. Leading Public Sector Innovation: Co-creating for a Better Society. Bristol, UK: The Policy Press.

Bekkers, V. (2009). Flexible information infrastructures in Dutch E-Government collaboration arrangements: Experiences and policy implications. Government Information Quarterly, 26(1), 60-68. doi:https://doi.org/10.1016/j.giq.2007.09.010

Bekkers, V., Tummers, L., \& Voorberg, W. (2013). From public innovation to social innovation in the public sector: A literature review of relevant drivers and barriers. Paper presented at the EGPA, Edinburgh, Scotland. 
Bertot, J., Jaeger, P., \& McClure, C. (2008). Citizen-centered e-government services: benefits, costs, and research needs, Paper presented at the International conference on Digital government research, Montreal, Canada.

Bucolo, S., \& C, W. (2013). Using a Design Led Approach to Emotional Business Modelling. Paper presented at the International Design Management Research Conference, Boston, MA.

Bucolo, S., \& Matthews, J. (2011). A conceptual model to link deep customer insights to both growth strategies and organizational strategy in SMEs as part of a design-led transformation journey. Paper presented at the Design Management: Towards a New Era of Innovation, Hong Kong, PRC.

Carter-Steel, A., Tan, W.-G., \& Toleman, M. (2009). itSMF Australia 2008 Conference: summary of ITSM standards and frameworks survey responses. Retrieved from Toowoomba:

Charette, R. (2005). Why Software Fails. IEEE Spectrum, 1-8. Retrieved from https://spectrum.ieee.org/computing/software/why-software-fails

Chesbrough, H., \& Spohrer, J. (2006). A Research Manifesto for Services Science. Communications of the ACM, 49(7), 35-40.

Cunningham, J. B., \& Kempling, J. S. (2009). Implementing change in public sector organizations. Management Decision, 47(2), 330-344.

Davenport, T. (2013). Analytics 3.0. Harvard Business Review, 91(12), 64-76.

De-Vries, H., Bekkers, V., \& Tummers, L. (2016). Innovation in the Public Sector: A Systematic Review and Future Research Agenda. Public Administration, 94(1), 146-166.

Denhardt, R. B., \& Denhardt, J. V. (2000). The New Public Service: Serving Rather than Steering. Public Administration Review, 60(6), 549-559.

Dorst, K., \& Cross, N. (2001). Creativity in the design process: co-evolution of problem-solution. Design Studies, 22(5), 425-437.

Dunleavy, P., Margetts, H., Bastow, S., \& Tinkler, J. (2006). New Public Management Is DeadLong Live Digital-Era Governance. Journal of Public Administration Research and Theory, 16(3), 467-494.

Esterhuizen, D., Schutte, C. S. L., \& du Toit, A. S. A. (2012). Knowledge creation processes as critical enablers for innovation. International Journal of Information Management, 32(4), 354-364.

Fakhoury, R., \& Aubert, B. (2015). Citizenship, trust, and behavioural intentions to use public eservices: The case of Lebanon. International Journal of Information Management, 35(3), 346-351.

Gassmann, O., \& Enkel, E. (2004). Towards a Theory of Open Innovation: Three Core Process Archetypes. Paper presented at the R\&D Management Conference (RADMA), Lisbon.

Gottschalk, P. (2009). Maturity levels for interoperability in digital government. Government Information Quarterly, 26(1), 75-81.

Hancox, M., \& Hackney, R. (1999). Information Technology Outsourcing: Conceptualizing Practice in the Public and Private Sector. Paper presented at the Hawaii International Conference on Systems Sciences (HICSS), Hawaii.

Highsmith, J., \& Cockburn, A. (2001). Agile Software Development: The Business of Innovation. Computer, 34(9), 120 - 127.

Hildenbrand, T., \& Meyer, J. (2012). Intertwining Lean and Design Thinking: Software Product Development from Empathy to Shipment. In A. Maedche, A. Botzenhardt, \& L. Neer (Eds.), Software for People: Fundamentals, Trends and Best Practices (pp. 217-237). Berlin, Heidelberg: Springer Berlin Heidelberg.

Hommen, L., \& Rolfstam, M. (2009). Public Procurement and Innovation: Towards a Taxonomy. Journal of Public Procurement, 9(1), 17-56.

Jansen, S., Finklestein, A., \& Brinkkemper, S. (2009). A Sense of Community: A Research Agenda for Software Ecosystems. Paper presented at the ICSE'09, Vancouver, Canada.

Janssen, M., Charalabidis, Y., \& Zuiderwijk, A. (2012). Benefits, Adoption Barriers and Myths of Open Data and Open Government. Information Systems Management, 29(4), 258-268.

Janssen, M., Konopnicki, D., Snowdon, J. L., \& Ojo, A. (2017). Driving public sector innovation using big and open linked data (BOLD). Information Systems Frontiers, 19(2), 189-195. 
Kowalkiewicz, M., Rosemann, M., Reeve, A., Townson, P., \& Briggs, A. (2016). The Proactive Organization. Retrieved from http://www.chairdigitaleconomy.com.au/wpcontent/uploads/2016/03/RPT_ProactiveOrganisation_FIN.pdf

Kyffin, S., \& Gardien, P. (2009). Navigating the innovation matrix: An approach to design-led innovation. International Journal of Design, 31(1), 57-69.

Lee, S., Baek, H., \& Jahng, J. (2017). Governance strategies for open collaboration: Focusing on resource allocation in open source software development organizations. International Journal of Information Management, 37(5), 431-437.

Lee, S., Olson, D., \& Trimi, S. (2012). Co-innovation: convergenomics, collaboration, and co-creation for organizational values. Management Decision, 50(5), 817-831.

Martin, D. (2004). The Business of Design. Rotman Management (Winter), 7-10.

Matthews, J., Bucolo, S., \& Wrigley, C. (2012). Challenges and opportunities in the journey of the design-led innovation champions. Paper presented at the DMI International Research Conference, Boston, MA.

Moon, J., Swar, B., Chan Choe, Y., Chung, M., \& Hyun Jung, G. (2010). Innovation in IT outsourcing relationships: Where is the best practice of IT outsourcing in the public sector? Innovation, 12(2), 217-226.

Nambisan, S. (2008). Transforming Government through Collaborative Innovation. 37(3), 36-41.

Norman, D. (2010). The research-practice gap: the need for translational developers. Interactions, 17(4), 9-12.

Norman, D., \& Verganti, R. (2014). Incremental and Radical Innovation: Design Research vs. Technology and Meaning Change. Design Issues, 30(1), 78-96.

Norris, D., \& Reddick, D. (2013). Local E-Government in the United States: Transformation or Incremental Change? Public Administration Review, 73(1), 165-175.

OECD. (2016). Digital Government Strategies for Transforming Public Services in the Welfare Areas. Retrieved from http://www.oecd.org/gov/digital-government/Digital-Government-StrategiesWelfare-Service.pdf

Ogilvie, T., \& Liedtka, J. (2011). Designing for growth: A design thinking toolkit for managers. NY, NY: Columbia University Press.

Omar, A., Weerakkody, V., \& Sivarajah, U. (2017). Digitally enabled service transformation in UK public sector: A case analysis of universal credit. International Journal of Information Management, 37(4), 350-356. doi:10.1016/j.ijinfomgr.2017.04.001

Osborne, S., Radnor, Z., \& Nasi, G. (2012). A New Theory for Public Service Management? Toward a (Public) Service-Dominant Approach. The American Review of Public Administration, 43(2), $135-158$.

Paagman, A., Tate, M., \& Furtmueller, E. (2015). An Integrative Literature Review and Empirical Validation of Motives for Introducing Shared Services in Government Organizations International Journal of Information Management, 35(1), 110-123.

Rehm, S.-V., Goel, L., \& Junglas, I. (2016). Information management for innovation networks - an empirical study on the "who, what and how" in networked innovation. International Journal of Information Management, 36(3), 348-359.

Rowley, J. (2011). e-Government stakeholders-Who are they and what do they want? International Journal of Information Management, 31(1), 53-62.

Schon. (1983). The reflective practitioner: How professionals think in action. New York, NY: Basic Books.

Schwaber, K. (2004). Agile Project Management with SCRUM. Redmond, United States: Microsoft Press.

Smith, P. G., \& Reinertsen, D. G. (1992). Shortening the Product Development Cycle. ResearchTechnology Management, 35(3), 44-49.

Steen, M., Manschot, M. A. J., \& De_Koning, N. (2011). Benefits of co-design in service design projects. International Journal of Design, 5(2), 53-60.

Tate, M., Hynson, R., \& Toland, J. (2006). The disconnect between the current orthodoxy of local government and the promise and practice of information technology management: An illustrative case study. Paper presented at the European Conference in Information Systems (ECIS), Gotenburn, Sweden. 
Tate, M., Johnstone, D., Toland, J., \& Hynson, R. (2007). How the Current Orthodoxy of Local Government is Failing IT Managers: An Illustrative Case Study. Electronic Government: An International Journal, 4(4), 509-526.

Torfing, J. (2016). Innovation in the Public Sector. Washington, DC: Georgetown University Press. Uppström, E., \& Lönn, C.-M. (2015). Core Aspects for Value Co-Creation in Public Sector. Paper presented at the Americas Conference on Information Systems, Puerto Rico.

Windrum, P. (2008). Innovation and Entrepreneurship in Public Services. In P. Windrum \& P. Koch (Eds.), Innovation in Pubic Sector Services: Entrepreneurship, Creativity and Management (pp. 3-20). Cheltenham, UK: Edward Elgar Publishing.

World_Economic_Forum. (2014). Outlook on the Global Agenda, 2014. Retrieved from: https://www.weforum.org/reports/outlook-global-agenda-2014 


\section{Appendix A: Sprint Overview}

This summarizes, at a high level, six of the innovation sprints.

Sprint Number

Title

Youth without

homes

Starting a new café

business in

Queensland early intervention

and access to

appropriate services
More strategic Example Artefacts/Outcomes

or more

technical?

$(\mathrm{S} / \mathrm{T})$

A persona of homeless youth

Research-based characterization of the origins, nature and degrees of homelessness

Workflow service mapping for where to go when confronted with housing emergencies

Mock-ups for mobile application

Principle that it is not necessary to be authenticated to access all services

Online service redesign options based on fully digital solutions,

removing the need to visit different agencies

Aggregation of agencies and steps required into a single digital space with a clear workflow

Interface prototypes, mock-ups and wireframes

JSON models for exchanging customer information between agencies

Identification of existing services and barriers to service access and

delivery

Aggregation of services available into a single digital space

Harmonization of eligibility criteria

Easy, up to date contact information for emergency assistance

Interface prototypes, mock-ups and wireframes

JSON models for accessing relevant information across agencies based on family profile

Improving internal tacit knowledge

sharing in

government agencies
Identification of problems associated with knowledge sharing and ideation of proactive services

Identification and articulation of organizational and cultural issues that prevent collaboration (for example, siloed data, competition between agencies) 
each person

Identification of facilitating factors (e.g. neutral space, and "implementation agnostic" ideation)

Additional development and articulation of principles of service ownership and knowledge sharing

Identification of general, infrastructural requirements to implement models of personalised government services

Enhanced understanding of the nature of life events, predictive and proactive services

Additional development, articulation, and prioritization of governing principles of access, data sharing, value, ownership of services and data, permission to access and share personal information Strategic presentation on attracting digital companies

Insights into factors business, infrastructure, cultural and life-style factors that contribute to investment attractiveness and business success.

Aggregation of business and life-style information metrics - for example, property values, school districts, visa and migration information, local and national environments and assistance for business start-ups. 
Appendix B: Sprint artefacts.

\begin{tabular}{|c|c|c|c|c|}
\hline Activity & Description & Theoretical Underpinning & Principle & Example \\
\hline $\begin{array}{l}\text { Define initial } \\
\text { problem space }\end{array}$ & \multicolumn{3}{|c|}{$\begin{array}{l}\text { Inherited from initial, triage of potential problems, and refined as part of sprint } \\
\text { incubation and planning }\end{array}$} & $\begin{array}{l}\text { The issue addressed } \\
\text { involves exploring } \\
\text { opportunities to enhance } \\
\text { youth engagement in } \\
\text { policy making. }\end{array}$ \\
\hline $\begin{array}{l}\text { Empathy } \\
\text { Interviews }\end{array}$ & $\begin{array}{l}\text { Initial customer } \\
\text { interviews to gain an } \\
\text { empathetic view of } \\
\text { the situation and } \\
\text { understand the } \\
\text { underlying problem. }\end{array}$ & $\begin{array}{l}\text { 'Designers always ask 'are } \\
\text { we solving the right } \\
\text { problem?' If you hand } \\
\text { designers a problem they } \\
\text { never just take it and solve } \\
\text { it. They question it, and that } \\
\text { comes from empathy - } \\
\text { from really understanding } \\
\text { the user and being } \\
\text { accustomed to questioning } \\
\text { models" (Martin, 2004, p. } \\
\text { 11) }\end{array}$ & $\begin{array}{l}\text { Maintain alignment with } \\
\text { program-level "why" } \\
\text { vision, maintain focus on } \\
\text { customer-centricity, } \\
\text { understanding of problem } \\
\text { contexts, proactive } \\
\text { solutions, and new } \\
\text { technology opportunities. }\end{array}$ & $\begin{array}{l}\text { Individuals interested in } \\
\text { starting a café are } \\
\text { interviewed to understand } \\
\text { their goals, challenges, } \\
\text { and perceptions of the } \\
\text { existing process. }\end{array}$ \\
\hline $\begin{array}{l}\text { Desktop } \\
\text { research }\end{array}$ & $\begin{array}{l}\text { Collecting data, best } \\
\text { practice and } \\
\text { theoretical insights. } \\
\text { Research literature } \\
\text { helps crystalize } \\
\text { concepts, and } \\
\text { provide content and } \\
\text { theoretical } \\
\text { underpinnings to } \\
\text { sometimes complex } \\
\text { or obscure situations. } \\
\text { Bridges the gap }\end{array}$ & $\begin{array}{l}\text { "Translational developers } \\
\text { are needed who can mine } \\
\text { the insights of researchers } \\
\text { and hone them into } \\
\text { practical, relatable and } \\
\text { useful results. Similarly, } \\
\text { translational developers } \\
\text { must help convert the } \\
\text { problems and concerns of } \\
\text { practice into the clear, } \\
\text { research based statements } \\
\text { that can drive researchers to } \\
\text { create new insights. Either }\end{array}$ & $\begin{array}{l}\text { Instantiate new vision of } \\
\text { the role of government as } \\
\text { facilitating collaboration } \\
\text { to allow public servants, } \\
\text { voluntary agencies, the } \\
\text { private sector, and } \\
\text { universities, to collaborate } \\
\text { to solve difficult problems }\end{array}$ & $\begin{array}{l}\text { Review of academic } \\
\text { literature shows that } \\
\text { issues of trust in } \\
\text { government comes into } \\
\text { play every time a new } \\
\text { policy is announced } \\
\text { (Fakhoury \& Aubert, } \\
\text { 2015). }\end{array}$ \\
\hline
\end{tabular}


between research and direction of translation is practice

Stakeholder Workshops

Persona

Creation
Flexible workshop Strategic design within a sessions with varying company has become more membership depending on the nature of the problem. Aim to build off desktop research, create a shared understanding of the problem context, offer an opportunity for visionary thinking, ideation and exploration

Develop a personal and profile of the customer the service is aimed at. Personas 1) capture empathy into the service conceptualization and definition; 2) provide a shared language that can be easily understood by all stakeholders adapted for the public sector context of "customer" very personal and human, they enhance your ability to build the empathetic understanding of customers that is at the heart of design thinking" (Ogilvie \& Liedtka, 2011)
As above, instantiate new vision of the role of government as facilitator of solutions to social problems.

Exemplify new publicsector innovation sourcing approach which brings together a variety of stakeholders on a neutral and creative problemsolving environment.

Address inflexibility in previous sourcing processes, yet manage risk with bounded "sprint" cycles

"because personas make the potentially abstract concept
Academics, public servants, investors and

business angels participated in a workshop on a Queensland IT ecosystem, aimed at encouraging more IT investment and start-ups.

My name is John, I am 19 years old, I live in

Caboolture. I dropped out of high school when I was

16. I have an 18 month old daughter, and I am currently sleeping on a couch at my friend's place. 
Customer

Journey

Mapping

Informed by empathy interviews and

stakeholder

workshops. Journey

maps trace the

customer "journey"

through

using/interacting

with the service.

Journey maps, in

combination with

personas provide a

simple narrative to

align the maturing

understanding of

customer "pains"

with the evolving

conceptual solution

"Journey mapping" (or experience mapping) is an ethnographic research method that focusses on tracing the customers "journey" as he or she interacts with an organization while in the process of receiving a service, with particular attention to the emotional highs and lows. Experience mapping is used with the objective of identifying needs that customers are often unable to articulate (Ogilvie \& Liedtka, 2011)

These artefacts become key reference points and a focus for shared dialogue, as agencies can identify their contributions to the

"journey", and the points at which sharing and

collaboration are required.

Problem

Framing
Maintain focus on the customer vision and emerging solutions

become more concrete.

Provide guidelines for design, understanding of value proposition, and evaluation.

position, and

We identified that in the current situation, in order to apply for a grant under the Advance Queensland program, currently, a candidate has to first check available grants on the website and evaluate their own eligibility. Failure to do this correctly may make them ineligible for a scheme even if they have put considerable effort into an application.

As a principle, the new service should include regular and early evaluations of eligibility based on interaction with the customer, to ensure that significant effort is directed only towards grants for which the applicant is eligible

Frame: understanding citizen well-being is not a problem unique to Queensland and public agencies do not have the resources to create and highlighting the ways

their customers,

stakeholders, and

other market players
"A creative event occurs as insight at pair is framed - what Schon called "problem framing". Studies of expert and outstanding designers
Enable appropriate creative input into collaborative sourcing of innovation.

Surfaces principles and assumptions held by stakeholders, including 
Value Proposition Creation perceive them. This surfaces key

principles and assumptions. The way a problem is framed has a large influence on the shape of the final solution

\section{Problem framing and} value proposition creation go hand in hand. The value proposition clearly and succinctly describes the value that the proposed solution has for the stakeholder

problems. This can be evaluated in the suggest this framing ability is crucial to high-level performances in creative design" (Dorst \& Cross, 2001, p. 435)

contentious and

incompatible ones.

The value proposition as a concept must consider, incorporate and be codesigned by all internal, external operational and strategic requirements of both the agency and the stakeholders, along a value chain maintain entirely new measures.

While existing metrics and information feeds may not meet all our information needs, they will meet many of them in a cost-effective and sustainable way.

Therefore, when investigating options for the measurement of wellbeing in Queensland, we will not build entirely new measures.

Well recognized international well-being metrics will be used, integrated and interpreted for the Queensland context

Maintains focus on the customer and the problem aims at attracting digital space as solution options businesses to Queensland, evolve and are evaluated.

with the aim of creating a desirable business and living environment for tech companies and skilled professionals.

This will boost investment, jobs, innovation, and international linkages 
course of stakeholder

interactions.

Co-Design

Ideation

(Concept and

Prototype

Building)
A general,

collaborative design approach, co-design

supports and works

with previously

elicited

understandings and

presents concepts

and options. It is a

way of unpacking

organizational

assumptions about

customer contexts

and issues to co-

design solutions

informed by the

previous

deliverables, which

may not have been

obvious at the outset.

\section{Ideation is the}

development of new

solutions of

stakeholder

problems. At this

point understandings

of the customer,

problem and value

propositions inform

the creation of

artefacts (these may

be technical IT

artefacts, process "the people involved in codesign - for example,

researchers, designers,

developers, managers, and

other stakeholders - first

identify the desired goals of

the service design project in

which they will work and to

which they will all

contribute, and then

carefully design these

goods and benefits, or

example by selecting

appropriate co-design

methods and applying these

in ways that contribute

optimally to the project"

(Steen, Manschot, \&

De_Koning, 2011, p. 59).

Human-centred design,

with its emphasis on

iterated observation,

ideation and testing is

ideally suited for

incremental innovation and

unlikely to lead to radical

innovation. Radical

innovation comes from

changes in either

technology or meaning.

Meaning driven innovation

has the potential to be
As above, instantiate new

vision of the role of

government as facilitator

of solutions to social

problems, and new public

ector innovation sourcing approach.

Enable appropriate

stakeholder input into

design of solutions.

Supports development,

alignment and co-

evolution of service

vision, process and IT

aspects of solution

simultaneously.

Allows iteration and

innovation
Researchers from QUT

and designers from a

digital media agency

worked together with

managers from the

Queensland Government

to explore the value of

digital identities.
A social game based on the concept of idea flow was proposed as a

potential solution for increased community engagement in issues. 
artefacts, or

principles). The

artefacts instantiate,

expose and reveal the

understandings of

customer problems

and solutions. A

variety of design

processes (including

more traditional IT

design processes and

tools, where

appropriate) are used

in tandem to create

rapid and customer-

focussed ideation
Concept and

Prototype

Testing

\section{Prototyping of}

processes or

technical (IT)

artefacts is an

essential aspect of

co-design. It allows

experimentation and

"fail fast"

approaches.

\section{Deep Customer \\ Insights}

(Internal

Workshops)

\section{The process of}

sharing and refining

insights captured

amongst subject-

driven through design

research (Norman \&

Verganti, 2014)

matter experts to find

meaning and inform

further understanding

or the core concepts "the process produces one or more experience

prototypes which are built

on user insights and created

using actual or producible

technology" (Kyffin \&

Gardien, 2009, p. 63)

Supports development, alignment and co-

evolution of service

vision, process and IT

aspects of solution

simultaneously.

Allows mini "fail fast"

iteration and innovation

cycles within sprint cycles

\section{Development of deep}

customer insights which

identify a latent or

untapped customer need

Draws together previous activities and deliverables in a collaborative process.
A digital "map" of the existing services addressing youth homelessness was created.

After several iterations, the original problem scope for creating a wellbeing indicator was reframed based on insights obtained from customers that were exposed to the initial prototype. 
The model of creative

design proposed by Maher

et al is based on a co-

evolution of the problem-

space and the solution-

space in the design process,

the problem-space and the

solution-space co-evolve

together with interchange

of information between the

two spaces (Dorst \& Cross,

$$
\text { 2001, p. 435) }
$$

Artefacts/Assets The outputs or outcomes of the sessions. These may be technical or serviceoriented. They may include service or process specifications (for example, JSON specifications), prototypes, wireframes, mock-ups, and implementation guidelines

Assumptions Constraints,

Refinement and enhancement of the vision and service or IT architectural principles emerging from the specific sprint, for example that the customer-first Principles principle is more important than the digital-first principle, therefore, other channels will be available.

We created a mock-up website that pre-filters grants available to various research centers based on some eligibility criteria.

The digital platform was conceived based on the assumption that internet penetration in the country will not regress. 
